\title{
ABORDAGENS DA EDUCAÇÃO AMBIENTAL E MUDANÇAS CLIMÁTICAS NO ENSINO FORMAL EM MOÇAMBIQUE
}

\author{
Manuel Pastor Francisco Conjo ${ }^{1}$ \\ David Benjamim Chichango ${ }^{2}$ \\ Arcidio José Tamele ${ }^{3}$ \\ Ermelinda José Simão ${ }^{4}$ \\ Ajosia da Lídia Basílio Muipela Antônio ${ }^{5}$ \\ Octávio Manuel de Jesus ${ }^{6}$
}

RESUMO: A educação ambiental é um processo contínuo e permanente de formação de uma população consciente para com os problemas ambientais, uma população que busca solução dos problemas ambientais presentes e que procura prevenir problemas ambientais futuros. Este artigo pretende compreender como a Educação Ambiental pode auxiliar na percepção das mudanças climáticas em Moçambique. Foram analisados os principais conteúdos de educcao ambiental seleccionados no ensino formal e as abordagens metodológicas da sua aplicação de modo a contribuir para o desenvolvimento da consciência ambiental nos alunos e consequente melhoria da qualidade ambiental rumo ao desenvolvimento sustentável. Para sua produção recorreu-se as pesquisas documental e bibliográfica, através de leitura, análise e selecção de diversos conteúdos que fazem parte deste. Analisados os programas de ensino, verificou-se que estão patentes conteúdos de educação ambiental tratando de matérias sobre os elementos do ambiente e as formas de preservação do ambiente, nas disciplinas de Português, Ciências Naturais e Ciências Sociais no ensino primário e no ensino secundário nas disciplinas de Geografia, Física, Química, Biologia e Agropecuária, e são estratégias metodológicas escolhidas para o tratamento de conteúdos sobre a educação ambiental, a ilustração, a observação,

\footnotetext{
' Doutorando em Ciência Florestal pela Universidade Federal de Viçosa - Minas Gerais -Instituição: Universidade Pedagógica de Maputo/Universidade Federal de Viçosa. Mestrado em Gestão Ambiental pela Universidade Pedagógica de Maputo - Moçambique. Bacharel e Licenciado em Ensino de Geografia pela Universidade Pedagógica de Maputo - Moçambique Técnico Superior em Higiene e Segurança no Trabalho e Meio Ambiente pela Ensine Moçambique.E-mail: pastorconjooo7@gmail.com

${ }^{2}$ Mestrando em Gestão Ambiental, Faculdade de Ciências da Terra e Ambiente, Universidade Pedagógica de Maputo, Moçambique. Prof. de Geografia, Licenciado em Ensino de Geografia, Faculdade de Ciências da Terra e Ambiente, Universidade Pedagógica de Maputo, Moçambique. Email: davidchitlhango@gmail.com

${ }_{3}^{3}$ Mestrando em Gestão Ambiental, Faculdade de Ciências da Terra e Ambiente, Universidade Pedagógica de Maputo, Moçambique. Licenciado em Gestão Ambiental, Faculdade de Ciências da Terra e Ambiente, Universidade Pedagógica de Maputo, Moçambique. E-mail: tamelinho73@gmail.com

${ }^{4}$ Mestranda em Gestão Ambiental, Faculdade de Ciências da Terra e Ambiente, Universidade Pedagógica de Maputo, Moçambique. Professora. Licenciada em Ensino de Física. Faculdade de Ciências Naturais e Matemática. Universidade Pedagógica de Maputo. E-mail: ermelindasimao@gmail.com

${ }^{5}$ Mestranda em Gestão Ambiental, Faculdade de Ciências da Terra e Ambiente, Universidade Pedagógica de Maputo, Moçambique. Bióloga. Licenciada em Ciências Biológicas, Universidade de Lúrio, Moçambique. E-mail: ajosiamuipela@gmail.com

${ }^{6}$ Doutor em Ciências Pedagógicas, moçambicano, funcionário do Ministério da Ciência, Tecnologia e Ensino Superior. Membro de Júri, Supervisor e Arguente nas Defesas de Monografias, Dissertações em Havana-Cuba e Maputo- Moçambique. Supervisor das teses de Doutoramento em Moçambique. Docente na Universidade Pedagógica de Maputo (desde 2006), categoria Professor Auxiliar. E-mail: Octaviomzoor@yahoo.es
} 
interpretação, análise, síntese e avaliação de fenómenos físico-naturais, reflexão conjunta, discussão em grupos e visitas de estudo, não obstante, não há clareza na inclusão de conteúdos sobre mudanças climáticas nos programas de ensino. Torna-se importante a convergência entre os vários campos de abordagem, como o uso da relação entre a educação ambiental e mudanças climáticas para a formação de uma sociedade resiliente aos impactos das mudanças climáticas.

Palavras-chave: Educação ambiental. Mudanças climáticas. Ensino. Moçambique.

ABSTRACT: Environmental education is a continuous and permanent process of training a population that is aware of environmental problems, a population that seeks to solve present environmental problems and that seeks to prevent future environmental problems. This article intends to understand how Environmental Education can help in the perception of climate change in Mozambique. The main contents of environmental education selected in formal education and the methodological approaches of its application were analyzed in order to contribute to the development of environmental awareness in students and the consequent improvement of environmental quality towards sustainable development. For its production, documentary and bibliographic research was used, through reading, analysis and selection of various contents that are part of it. After analyzing the teaching programs, it was found that environmental education contents are evident, dealing with matters on the elements of the environment and ways of preserving the environment, in the subjects of Portuguese, Natural Sciences and Social Sciences in primary and secondary education in disciplines of Geography, Physics, Chemistry, Biology and Agriculture, and are methodological strategies chosen for the treatment of contents on environmental education, illustration, observation, interpretation, analysis, synthesis and evaluation of physical-natural phenomena, joint reflection, discussion in groups and study visits, however, there is no clarity in the inclusion of content on climate change in teaching programs. The convergence between the various fields of approach is important, such as the use of the relationship between environmental education and climate change to form a resilient society to the impacts of climate change.

Keywords: Environmental education. Climate change. Teaching. Mozambique.

\section{INTRODUÇẪO}

A educação ambiental é, na perspetiva de MARCATTO (2002:12), uma das ferramentas existentes para a sensibilização e capacitação da população em geral sobre os problemas ambientais. Com ela, busca-se desenvolver técnicas e métodos que facilitem o processo de tomada de consciência sobre a gravidade dos problemas ambientais e a necessidade urgente de nos debruçarmos seriamente sobre eles. 
Devido às mudanças climáticas, Moçambique é um país com uma elevada frequência, alternância e intensidade de eventos extremos, sobretudo ciclones, cheias e secas.

A vulnerabilidade de Moçambique a eventos extremos resulta da sua localização a jusante de nove rios internacionais, da existência de zonas áridas e semiáridas e ainda pelo facto do País possuir uma extensa zona costeira que sofre a influência de ciclones tropicais e de perdas e ganhos excessivos de humidade (REPÚBLICA DE MOÇAMBIQUE. CONSELHO DE MINISTROS, 20I8).

Em Moçambique, em relação a Educação ambiental, o actual currículo do Ensino Geral geral educa a criança, o jovem e o adulto para o respeito e preservação do ambiente e dos ecossistemas, garantindo que este conheça o meio em que vive, isto é, conheça as leis da natureza e as formas de preservação da mesma e desenvolva competências sobre práticas relevantes na área da agricultura e pecuária.

Este artigo, pretende compreender como a Educação Ambiental pode auxiliar na percepção das mudanças climáticas em Moçambique, trazendo e analisando os principais conteúdos selecionados e as abordagens metodológicas da sua aplicação de modo a contribuir para o desenvolvimento da consciência ambiental e resiliência aos impactos das mudanças climáticas nos alunos e consequente melhoria da qualidade ambiental rumo ao desenvolvimento sustentável.

\section{CONTEXTUALIZAÇẪO SOBRE EDUCAÇẪO AMBIENTAL $\quad \mathrm{E}$ MUDANÇAS CLIMÁTICAS}

\section{2.r. A definição e objectivos da educação ambiental}

Existem várias definições de educação ambiental, porém, o Congresso de Belgrado, promovido pela UNESCO em 1975, definiu a educação ambiental como sendo um processo que visa formar uma população mundial consciente e preocupada com o ambiente e com os problemas que lhe dizem respeito, uma população que tenha os conhecimentos, as competências, o estado de espírito, as motivações e o sentido de participação e engajamento que lhe permita trabalhar individualmente e 
coletivamente para resolver os problemas atuais e impedir que se repitam, apud (SEARA, 1987).

No Capítulo 36 da Agenda 21, a educação ambiental é definida como o processo que busca desenvolver uma população que seja consciente e preocupada com o meio ambiente e com os problemas que lhes são associados. Uma população que tenha conhecimentos, habilidades, atitudes, motivações e compromissos para trabalhar, individual e coletivamente, na busca de soluções para os problemas existentes e para a prevenção dos novos. (Capítulo 36 da Agenda 21).

Segundo DIAS (1999:II), a Educação para o Meio Ambiente possui como objectivo formar pessoas conscientes que lutem para a obtenção de um sistema de desenvolvimento do qual resultará em qualidade de vida para todos, ou seja, um desenvolvimento sustentável. E para que se consiga tal êxito, a Agenda 2i propõe que "tanto o ensino formal como o não formal são indispensáveis para modificar as atitudes das pessoas para que estas tenham capacidade de avaliar os problemas do desenvolvimento sustentável e abordá-los”.

Os objectivos da Educação Ambiental constituem em despertar atitude e criatividade, competência aos individuos a desenvolver acções e busca de solução para problemas ambientais, capacidade de avaliação, promover participação, responsabilidade, interferência e decisões em relação aos problemas ambientais rumo ao desenvolvimento sustentável. A Educação ambiental é uma ferramenta para o processo de desconstrução e reconstrução do pensamento, na medida em através dela pode se mudar a forma de pensar e agir das sociedades actuais para que possamos inverter o quadro de degradação ambiental rumo ao desenvolvimento sustentável.

Segundo ALVA (1997:16), apud BORGES e SANTOS (2008:2), a Educação Ambiental tem como objectivo principal levar os indivíduos à conscientização do ambiente em que vivem, do global e dos problemas neles existentes, motivando-os à mudança de comportamento, tornando-os comprometidos com a protecção e utilização dos recursos naturais de forma racional, hoje, e como também para o futuro, através de programas de incentivo à preservação e recuperação ambiental, 
potencializa-se a preservação e a indução de actividades combatíveis com a realidade ambiental do lugar.

"A educação, seja formal, informal, familiar ou ambiental, só é completa quando a pessoa pode chegar nos principais momentos de sua vida a pensar por si próprio, agir conforme os seus princípios, viver segundo seus critérios" (REIGOTA, 1995), apud (OLIVEIRA e MEDEIROS, 2010).

Tendo essa premissa básica como referência, de acordo com MARCATTO (2002), propõe-se que a Educação Ambiental seja um processo de formação dinâmico, permanente e participativo, no qual as pessoas envolvidas passem a ser agentes transformadores, participando activamente da busca de alternativas para a redução de impactos ambientais e para o controle social do uso dos recursos naturais.

\subsection{Princípios gerais da Educação Ambiental}

Para BORGES e SANTOS (2008), a educação ambiental é orientada pelos seguintes princípios: Sensibilização, Compreensão, Responsabilidade, Cidadania e

\section{Competência.}

Conforme COLESANTI (2008), a E.A é um processo de aprendizagem permanente que promove respeito ao ambiente. Ela estimula a formação de sociedades justas e ecologicamente equilibradas, com diversidade. A Educação Ambiental possui uma força de transformação, pois leva a realização de crítica da conduta pessoal, permite pensamento e prática comprometida, superação os diversos interesses, luta em defesa do direito de desfrutar do meio ambiente, compreensão crítica e global do ambiente que promova conservação e a adequada utilização dos recursos naturais.

\subsection{Características da educação ambiental}

De acordo com a Conferência de Tbilisi, ocorrida em 1977, na ex-União Soviética, apud MARCATTO (2002:I8), a educação ambiental tem como principais características ser um processo: dinâmico e integrativo, transformador, participativo, abrangente, permanente, globalizador, contextualizador e transversal. 
A educação ambiental vista como um agente de transformação exige uma profunda mudança de valores, atitudes, "uma nova visão de mundo, o que ultrapassa bastante o universo meramente conservacionista" (BRUGGER, 1999:34), apud (OLIVEIRA e MEDEIROS, 20I0).

De acordo com ADAMS (2005), a partir da Eco 92 a Educação ambiental se caracteriza por incorporar as dimensões sócio-econômica, política, cultural e histórica, devendo considerar as condições e estágios de cada país, região e comunidade, sob uma perspectiva histórica, permitindo a compreensão da natureza complexa do meio ambiente, com vistas a utilizar racionalmente os recursos do meio na satisfação material e social da sociedade, no presente e no futuro.

Assim, essa educação não visa somente apontar os problemas de degradação ambiental, poluição, uso inadequado de recursos, mas sim, entender o porquê desses problemas, suas raízes históricas, sociais, culturais e no caso da sociedade capitalista, principalmente a econômica. Levantando assim hipóteses e propostas de possíveis acções em prol da vida humana, que é dependente e constituinte da natureza (OLIVEIRA e MEDEIROS, 20I0).

Deste modo, a educação ambiental desempenha um papel bastatnte importante contribuindo para a formação de cidadãos conscientes, preparados para participar activamente na busca de soluções para os problemas socioambientais comprometidos com o equilibrio entre a sociedade e o ambiente.

\subsection{Estratégias de abordagem da Educação Ambiental no contexto escolar}

Existem diferentes formas de incluir a educação ambiental nos currículos escolares tais como, actividades artísticas, experiências práticas de sala de aula, produção de materiais locais, projectos ou qualquer outra actividade que conduza os alunos a serem reconhecidos com agentes activos no processo que norteia o ambientalismo.

Segundo DIAS (1992), a Conferência de Tbilisi realizada em 1977 já demonstrava as preocupações existentes a esse respeito, mencionando, em um dos pontos da recomendação $\mathrm{n}^{\circ}$ 2I, que deveriam ser efectuadas pesquisas sobre os 
obstáculos inerentes ao comportamento ambiental, que se opõem às modificações dos conceitos, valores e atitudes das pessoas.

Para SANTOS (2008), cabe aos professores, por intermédio da prática interdisciplinar, promoverem novas metodologias que favoreçam a implementação da educação ambiental, sempre considerando o ambiente imediato, relacionado a exemplos de problemas actualizados.

MONJANE et al (2010), defendem que:

A educação ambiental, como tema transversal, pode ser implementada através de acções concretas tais como: realização de excursões com visita a aliar a teoria e a prática, realização de palestras sobre aspectos ambientais (questões em discussão nos Mídias), elaboração de matérias de divulgação e propaganda de aspectos ambientais, campanha de plantio de árvores para fins energéticos nas zonas rurais, criação de jardins de plantas para fins medicinais, promoção de concursos entre escolas sobre a poupança de energia e uso sustentável da água, promoção de palestras sobre o uso de fruteiras nativas para nutrição do Homem e a importância das mesmas para a conservação da biodiversidade, divulgação, através de posters e exposição da regra de $3 R^{\prime}$ s, promoção de acções de compostagem nas comunidades (MONJANE et al, 2010).

Portanto, deve-se buscar alternativas que promovam uma contínua reflexão

que culmine na mudança de mentalidade sobre, pois apenas dessa forma conseguiremos implementar, nas nossas escolas, a verdadeira educação ambiental, como actividades e projectos não meramente ilustrativos, mas fruto da ânsia de toda a comunidade escolar em construir um futuro no qual possamos viver num ambiente equilibrado, em harmonia com o meio, com os outros seres vivos e com nossos semelhantes (CONCEIÇẪO et al 2016:16).

De acordo com DIAS (2004:219)

podem ser aplicadas diversas estratégias de ensino para a prática da educação ambiental, tais como: discussão em classe, envolvendo todos; discussão em grupo; mutirão de idéias, quando pequenos grupos sugerem soluções para um dado problema, porém, sem se preocupar com análise crítica, num tempo de Io a 15 minutos; trabalho de grupos; debate ; questionário; reflexão, que envolve a análise crítica; imitação da mídia; projectos; solução de problemas, que considera a apresentação e solução de problemas; jogos de simulação, operacionalização de situações reais referentes a um problema; e por fim exploração do ambiente local, por meio de observações (DIAS, 2004:219).

OLIVEIRA e MEDEIROS (2010) destacam que para um programa de educação ambiental ser efectivo, deve promover, simultaneamente, o 
desenvolvimento de conhecimento, de atitudes e de habilidades necessárias à preservação e melhoria da qualidade ambiental.

Para TRISTÃO (2004), é necesssrio abordar a educação ambiental como algo próximo, ou seja, é evidente que temos problemas globais que devem ser discutidos, todavia, se não sabemos ou entendemos o que ocorre em nosso bairro, ou cidade, ou mesmo em nossas casas, como analisar questões mais amplas?

\subsection{A Educação Ambiental no contexto das mudanças climáticas}

O estudo da eficiência de uma educação interdisciplinar em mudanças climáticas, com vistas a uma alteração do comportamento e das actividades antrópicas, ainda é incipiente e pouco aplicado no mundo, entretanto é bastante relevante para o contexto actual.

As mudanças climáticas estão entre os principais temas da política mundial, uma vez que seus efeitos afectam a humanidade nos contextos social, ambiental, cultural e econômico. As causas e efeitos das mudanças climáticas interligam o passado, o presente e o futuro da história da humanidade, interferindo na vida humana nos níveis pessoal e global (UNESCO, 2005)

Nesse sentido, urge a necessidade de os decisores políticos melhorarem a compreensão dos efeitos sistêmicos das mudanças climáticas e fornecerem um maior suporte à educação, para que esta possa trazer respostas mais eficientes ( FERNANDES, 2015).

LIMA e LAYRARGUES, (2014), explicam que:

Os processos educativos podem ampliar a compreensão do fenômeno climático, de sua gênese histórica, de suas causas estruturantes, de suas múltiplas dimensões, em especial as condicionantes políticas e culturais menos aparentes e das alternativas de sua superação, disponíveis para os indivíduos, grupos, movimentos sociais, empresas e governos. Sabe-se que a educação não actua directamente sobre os problemas sociais, mas indirectamente sobre a consciência dos indivíduos e de sua capacidade de atribuir significados às relações sociais, à relação entre a sociedade e o ambiente e de agir de acordo com os sentidos construídos (LIMA e LAYRARGUES, 2014). 
A aquisição e divulgação do conhecimento a respeito dos processos relacionados às mudanças climáticas devem criar condições favoráveis para desenvolver adaptações e medidas de mitigação eficientes.

São inúmeros os campos de abordagem nesse aspecto: o uso da relação entre a educação ambiental, alfabetização científica e mudança climática; mudança curricular formal e não formal; a história da mudança climática e sua relação com o modelo social; o conhecimento melhorado dos eventos climáticos, modelos de consumo, incertezas e estatísticas climáticas; o aproveitamento do seu carácter polêmico no ensino de ciências naturais; a análise de mitigações eficientes (MOCHIZOKI, 2015) apud (FERNANDES e BARBOSA, 2016).

Essas abordagens, entre outras, visam a aprendizagem de novos conhecimentos e habilidades e a mudança de comportamentos, a fim de reduzir as vulnerabilidades e gerir os riscos das mudanças climáticas nos ambientes vivenciais. Com efeito, para conseguir a realização dos objectivos, é necessária uma ampla reforma com alto investimento financeiro para o sector educacional (FERNANDES e BARBOSA, 2016).

\section{MATERIAIS E MÉTODOS}

Para produção deste artigo recorreu-se à pesquisa ou metodologia qualitativa, que para HEIDRICH e PIRES (20I6), compreende a prática ou conjunto de procedimentos voltados à colecta de informações que envolvem o uso da linguagem, em geral objectivadas para a captura de subjetividades e/ou significados contidos nos textos.

A colecta de informação foi efectuada através das pesquisas bibliográfica e documental, que segundo MARCONI e LAKATOS (2003:19o), abrangem toda bibliografia já tornada pública em relação ao tema de estudo. Neste âmbito, a pesquisas bibliográfica e documental foi realizada através de leitura, análise e selecção de informação já escrita em livros, artigos, monografias, dissertações, teses e em programas dos ensinos primário e secundários em uso no país, materiais 
disponíveis em bibliotecas e na internet, abordando os conteúdos que fazem corpo desta pesquisa

\section{APRESENTAÇẪO DOS RESULTADOS}

\section{Resultado I. Abordagem da Educação Ambiental no Ensino Primário em Moçambique.}

No contexto do Ensino Primário, o papel das Ciências Naturais e Sociais é iniciar o aluno no seu envolvimento na protecção e conservação do meio ambiente; formar um cidadão responsável pela sua conduta pessoal e pelo apoio ao desenvolvimento da comunidade, país, continente e do mundo; desenvolver, através de uma abordagem sistemática, atitudes/valores, comportamentos, capacidades, habilidades e conhecimentos que permitirão ao aluno valorizar as relações humanas, observar, interpretar, analisar, sintetizar e avaliar os fenómenos naturais.

Os alunos em casa podem produzir cartazes, cartões ou quadros murais com imagens de agentes poluentes e contaminantes. Os materiais didácticos podem servir de modelo para debates sobre a acção do homem no seu dia-a-dia nas cidades e no campo. A escola pode organizar uma excursão para visitar zonas poluídas/contaminadas pela acção do Homem. Os alunos em grupos poderão produzir cartazes que mostram as formas de prevenção de doenças provocadas pelo consumo de água poluída/contaminada. A turma pode criar um jornal de turma / escola para promover atitudes e valores sobre forma de estar, ser na comunidade escolar. A escola pode organizar actividades de limpeza nos rios, lagos ou mares (praias), colocar colectores do lixo para papel, plástico e garrafas. No município ou na comunidade, os alunos podem organizar palestras sobre as consequências do uso de águas contaminadas/poluídas para a saúde.

Visitar o recinto da escola, floresta nativa ou comunitária, canteiro da escola/ou uma machamba para a identificação e classificação das plantas (erva, arbusto, árvores de grande/pequeno porte) da sua comunidade. Depois de identificar, classificar e dar nomes far-se-á referência à importância de cada planta na comunidade (económica, medicinal e cultural). Em colaboração com os 
extensionistas e os agricultores, os alunos podem aprender as técnicas de produção de plantas. A escola pode organizar com a comunidade jornadas de reflorestamento.

Resultado I.I. Quadro dos conteúdos sobre educação ambiental presentes nos programas do Ensino Primário em Moçambique

\begin{tabular}{|c|c|c|}
\hline CLASSE & CONTEÚDOS SOBRE EDUCAÇÃO AMBIENTAL & ESTRATÉGIAS \\
\hline $\mathbf{I}^{\mathrm{a}}$ Classe & $\begin{array}{l}\text { Disciplina de Português } \\
\text { Ambiente (elementos e preservação); } \\
\text { Os animais domésticos e selvagens, e sua utilidade. As } \\
\text { plantas e as suas partes. Formas de protecção das plantas. } \\
\text { Importância da água. }\end{array}$ & $\begin{array}{l}\text { Cancões sobre o } \\
\text { ambiente, observação do } \\
\text { meio e ilustração. }\end{array}$ \\
\hline $2^{\text {a }}$ Classe & $\begin{array}{l}\text { Disciplina de Português } \\
\text { Descreve, oralmente, o ambiente, distinguindo os seres } \\
\text { vivos dos não vivos e preservação. } \\
\text { Descreve os animais domésticos e selvagens e sua } \\
\text { utilidade. } \\
\text { Descreve regras de higiene alimentar e do meio. }\end{array}$ & $\begin{array}{l}\text { Canções sobre o meio } \\
\text { ambiente, observação do } \\
\text { meio e ilustração. }\end{array}$ \\
\hline $3^{\text {a }}$ Classe & $\begin{array}{l}\text { Disciplina de Português } \\
\text { Tema transversal: Animais domésticos e selvagens. } \\
\text { Tema transversal: Plantas } \\
\text { Expressões sobre o estado do tempo }\end{array}$ & $\begin{array}{l}\text { Imagens, os diálogos, as } \\
\text { histórias, } \\
\text { dramatizações, as } \\
\text { recontos, as canções e os } \\
\text { jogos. }\end{array}$ \\
\hline \multirow[t]{2}{*}{$4^{\text {a }}$ Classe } & $\begin{array}{l}\text { Disciplina de Português } \\
\text { Tema transversal: - Os animais (animais domésticos e } \\
\text { selvagens, importância dos animais). } \\
\text { Tema transversal: Formas de conservação e tratamento } \\
\text { da água. }\end{array}$ & \multirow[t]{2}{*}{$\begin{array}{l}\text { Imagens, os diálogos, as } \\
\text { histórias, } \\
\text { dramatizações, as } \\
\text { recontos, as canções e os } \\
\text { jogos, observação do } \\
\text { meio. }\end{array}$} \\
\hline & $\begin{array}{l}\text { Disciplina de Ciências Sociais } \\
\text { Características físico-geográficas de Moçambique: } \\
\text { Relevo, clima, rios, lagos, flora e fauna. } \\
\text { Conservação e preservação do ambiente. }\end{array}$ & \\
\hline \multirow[t]{2}{*}{$5^{\mathbf{a}}$ Classe } & $\begin{array}{l}\text { Disciplina de Português } \\
\text { Tema transversal: Preservação do ambiente. } \\
\text { Exposição oral ou escrita Tema transversal: as riquezas } \\
\text { do nosso país. }\end{array}$ & \multirow{2}{*}{$\begin{array}{l}\text { Imagens, os diálogos, as } \\
\text { histórias, } \\
\text { dramatizações, as } \\
\text { recontos, as canções e os } \\
\text { jogos, observação do } \\
\text { meio. }\end{array}$} \\
\hline & $\begin{array}{l}\text { Disciplina de Ciências Naturais } \\
\text { Caca, pesca, conservação da água, solo, higiene e } \\
\text { ambiente. }\end{array}$ & \\
\hline
\end{tabular}




\begin{tabular}{|c|c|c|}
\hline & $\begin{array}{l}\text { Disciplina de Ciências Sociais } \\
\text { Características físico-geográficas de Moçambique: } \\
\text { Relevo, clima, rios, lagos, flora e fauna, } \\
\text { Preservação do Ambiente: Conservação e preservação do } \\
\text { Ambiente (água; solos de produção agrícola e extracção } \\
\text { mineira; solos de produção agrícola e extracção mineira). }\end{array}$ & \\
\hline 6a Classe & $\begin{array}{l}\text { Disciplina de Ciências Naturais } \\
\text { Causas da poluição da água Tipos de poluição } \\
\text { (doméstica, agropecuária e industrial) Doenças } \\
\text { provocadas por poluição da água (cólera, diarreias, } \\
\text { malária, bilharziose) Formas de prevenção da poluição } \\
\text { da água. } \\
\text { Acção do homem sobre o solo e suas consequências: } \\
\text { Queimadas descontroladas } \\
\text { Agricultura (monocultura). Desflorestamento Técnicas } \\
\text { de protecção do solo. } \\
\text { Plantas mais comuns na comunidade. Importância de } \\
\text { produção de plantas na comunidade. } \\
\text { Fontes de energia (sol, água, vento, lenha, carvão } \\
\text { mineral e vegetal) Tipos de energia (eléctrica, calorífica, } \\
\text { eólica). } \\
\text { Disciplina de Ciências Sociais } \\
\text { África: Localização geográfica, Litoral e o seu traçado. } \\
\text { Características físico-geográficas gerais: (relevo, clima, } \\
\text { fauna, flora, principais rios e lagos) }\end{array}$ & $\begin{array}{l}\text { Observação, } \\
\text { Interpretação, } \\
\text { Analise, } \\
\text { Síntese e } \\
\text { Avaliação de fenómenos. }\end{array}$ \\
\hline \multirow[t]{2}{*}{$7^{\text {a }}$ Classe } & $\begin{array}{l}\text { Disciplina de Ciências Naturais } \\
\text { Agentes poluentes do solo, da água e do ar. Efeitos da } \\
\text { poluição no ambiente (destruição da vegetação, e } \\
\text { mortalidade dos seres vivos); Cadeia e teia alimentar } \\
\text { Fertilização (rotação das culturas, adubação orgânica e } \\
\text { inorgânica); Risco em caso de relâmpago e para-raios; } \\
\text { Papel das comunidades na gestão dos recursos } \\
\text { faunísticos; Instrumentos de caça. Caça autorizada e sua } \\
\text { importância e Caça furtiva e suas consequências; Papel } \\
\text { das comunidades na gestão dos recursos pesqueiros; } \\
\text { Instrumentos de pesca; Pesca autorizada (média e de } \\
\text { grande escala) e sua importância; Pesca artesanal e sua } \\
\text { importância na comunidade. } \\
\text { Pesca furtiva e suas consequências. Acção da } \\
\text { temperatura sobre os corpos. }\end{array}$ & \multirow[t]{2}{*}{$\begin{array}{l}\text { Observação, } \\
\text { Interpretação, } \\
\text { Analise, } \\
\text { Síntese e } \\
\text { Avaliação de fenómenos. }\end{array}$} \\
\hline & $\begin{array}{l}\text { Disciplina de Ciências Sociais } \\
\text { Aspectos físico-geográficos gerais dos continentes. } \\
\text { (Europa, Asia, América) }\end{array}$ & \\
\hline
\end{tabular}

Fonte: Adaptado pelos autores a partir dos programas do ensino primário 


\section{Resultado 2. Abordagem da Educação ambiental no Ensino Secundário Geral em Moçambique}

Em Moçambique, o actual currículo do Ensino Secundário Geral caracterizase por ser orientado para a continuação dos estudos no Ensino Superior. Neste contexto, em relação a Educação ambiental, o ensino secundário geral educa a criança, o jovem e o adulto para o respeito e preservação do ambiente e do ecossistema, garantindo que este conheça o meio em que vive, isto é, conheça as leis da natureza e as formas de preservação da mesma e desenvolva competências sobre práticas relevantes na área da agricultura e pecuária.

A transversalidade da Educação Ambiental corresponde, a forma como os temas são incorporados no currículo no que diz respeito à sequência, continuidade e aprofundamento bem como à maneira como são tratados do ponto de vista didáctico, por forma a estabelecer uma ligação com a vida real. Neste contexto, foram seleccionados os seguintes temas: Ambiente e uso sustentável dos recursos naturais; desastres naturais (cheia, seca, ciclone, sismo). A abordagem destes temas pressupõe um trabalho de planificação conjunta entre os professores, na sala de aula e nas actividades cocurriculares.

A realização de projectos destaca-se entre as formas de concretização deste tipo de abordagem, pois mobiliza professores de várias disciplinas, alunos de uma turma ou mais, permite desenvolver um leque variado de competências e faz convergir várias áreas de conhecimento em torno de uma ideia e projectos comuns. A leccionação destes temas exige ainda que se faça uma reflexão conjunta dos conteúdos a serem leccionados em cada um dos temas e as respectivas estratégias. Estas deverão privilegiar a discussão, a possibilidade de confrontar, argumentar e propor mudanças. O estudo dos conteúdos referentes a cada um dos temas não se esgota no ambiente de sala de aula, devendo ser extensivo a outros espaços menos formais tais como os círculos de interesse, encontros juvenis, clubes, entre outros agrupamentos.

Em relação a Educação ambiental, na disciplina de Geografia ao longo do Io Ciclo do ensino secundário geral, orienta-se para o desenvolvimento de competências 
gerais relevantes para a vida, promovendo conhecimentos, habilidades e atitudes correctas perante à natureza e à sociedade; desenvolver, nos alunos, uma crescente consciência acerca das oportunidades e constrangimentos que afectam os povos tendo em conta diferentes condições naturais, económicas, sociais, políticas, em cada lugar; desenvolver, nos alunos, uma melhor compreensão da natureza das sociedades multiculturais e multiraciais, contra quaisquer formas de preconceitos.

$\mathrm{Na}$ disciplina de Biologia, a aprendizagem visa contribuir para a compreensão científica do mundo através da utilização dos conhecimentos biológicos na explicação da unidade e diversidade da matéria viva, desenvolver habilidades que permitam ao aluno aplicar os conhecimentos na resolução de problemas específicos, quer da disciplina quer da vida prática social, mediante observações, a realização de experiências, excursões, manipulação de instrumentos, aplicação de teorias, leis e princípios no estudo de fenómenos biológicos, criar nos alunos o amor pela natureza, estabelecendo relações afectivas com os organismos; contribuir para a protecção, conservação e uso sustentável dos recursos naturais, em especial da diversidade biológica do nosso país, em benefício da sociedade actual e futura.

$\mathrm{Na}$ disciplina de Química pretende-se capacitar os alunos para a correcta utilização das teorias e leis na resolução dos problemas práticos e na explicação dos fenómenos que ocorrem na Natureza.

$\mathrm{Na}$ disciplina de Física pretende-se que a aprendizagem contribua para a formação de uma cultura de ciência e tecnologia efectiva, que permita ao aluno a interpretação dos factos, fenómenos e processos naturais. Portanto, a Física deverá promover um conhecimento contextualizado e integrado na vida do aluno. $\mathrm{O}$ ensino da Física visa desenvolver, nos alunos, competências que lhes permitam resolver problemas do dia a dia relacionados com fenómenos naturais ou com a tecnologia, usando criativamente leis, princípios e conceitos físicos.

A introdução da disciplina de Agro-Pecuária no Ensino Secundário Geral visa desenvolver competências práticas e tecnológicas que lhes permitam contribuir para a redução da vulnerabilidade e da pobreza absoluta no país, através da aplicação de novas técnicas de produção agro-pecuária, conservação dos produtos agro-pecuários 
bem como utilização racional de recursos disponíveis, desenvolvendo, nos alunos, a compreensão da importância da agro-pecuária no desenvolvimento rural e do país; e desenvolver, nos alunos, atitudes e hábitos positivos em relação à Agro-Pecuária;

Moçambique possui um grande potencial turístico que urge desenvolver. A aprendizagem do Turismo no Ensino Secundário Geral visa desenvolver competências que permitam os alunos conhecer as perspectivas de desenvolvimento do turismo e os principais locais (destinos) turísticos em Moçambique; conhecer o impacto do turismo na economia, na sociedade e sobre o ambiente

\section{CONSIDERAÇÕES FINAIS}

Das análises efectuadas em diferentes materiais e nos programas de ensino primário e secundário aplicados em Moçambique, consta a grande preocupação de incorporar a questão ambiental no ensino formal, sendo que sua materialização e aplicação é de forma transversal aproveitando os conteúdos específicos de cada disciplina. Neste contexto, de um modo geral foram seleccionados os seguintes temas: Ambiente, recursos naturais, uso sustentável dos recursos naturais; desastres naturais (cheia, seca, ciclone, sismo). A abordagem destes temas pressupõe um trabalho de planificação conjunta entre os professores, na sala de aula e nas actividades cocurriculares. Analisados os programas de ensino verifica-se que no ensino primário estão patentes conteúdos de educação ambiental nas disciplinas de Português, Ciências Naturais e Ciências Sociais e no ensino secundário nas disciplinas de Geografia, Física, Química, Biologia e Agropecuária. São estratégias metodológicas escolhidas para o tratamento de conteúdos sobre a educação ambiental, a ilustração, a observação, interpretação, análise, síntese e avaliação de fenómenos físico-naturais, reflexão conjunta, discussão em grupos e visitas de estudo. Torna-se importante a convergência entre os vários campos de abordagem, como o uso da relação entre a educação ambiental e mudanças climáticas; o conhecimento melhorado dos eventos climáticos, modelos de consumo, incertezas e estatísticas climáticas, sendo que o aproveitamento do seu carácter polêmico no ensino de ciências naturais pode trazer resultados positivos a longo prazo, formando 
deste modo uma populacao consciente para com os problemas ambientais, uma população capaz de aplicar medidas resilientes face aos prblemas ambientais. $O$ grande desafio é formar professores preparados para o tratamento seguro dos conteúdos sobre a educação ambiental e mudanças climáticas.

\section{REFERÊNCIAS BIBLIOGRÁFICAS}

ADAMS. B.G. "O que é Educação Ambiental"? Disponível em Anselmo, G. C. S. e Cardoso, J. A. F. Educação Ambiental no Contexto do Semiárido. 2005.

BORGES, Adairlei e SANTOS, Helaine. Educação ambiental: Conceitos, objectivos, e directrizes. Santa Mónica. Universidade Federal de Uberlândia. 2008.

COlESANTI, M.T. M. Educação Ambiental e as novas tecnologias de Informação e comunicação. Uberlândia. Sociedade \& Natureza. 2008.

CONCEIÇẪO, A. et al. Oportunidade para ensinar e aprender educação ambiental no $I^{\underline{0}}$ ciclo do ensino secundário geral em Moçambique. Maputo. Editora Educar/Universidade Pedagógica. 2016.

DIAS, S. Educação Ambiental: princípios e práticas. São Paulo. Editora Gaia. 1992.

DIAS, Genebaldo. Freire. Elementos para capacitação em Educação Ambiental. Ilhéus. Editus. 1999.

DIAS, Genebaldo Freire. Educação Ambiental: princípios e práticas. 9. Ed. São Paulo. Editora Gaia. 2004.

FERNANDES, Silva, Costa. Mudanças climáticas e ambientais: Contextos educacionais e históricos. Natal. IFRN.2015.

FERNANDES, Silva, Costa e BORBOSA . A educação em mudanças climáticas: uma abordagem interdisciplinar. Rede de Revistas Científicas da América Latina. Caribe. Espanha e Portugal. 2016.

HEIDRICH, A. e PIRES, C. Abordagens e práticas de pesquisa qualitativa em Geografia e saberes sobre espaço e cultura. Porto Alegre. Editora Letra. 2016. 
INDE. MINISTÉRIO DE EDUCAÇÃO E DESENVOLVIMENTO HUMANO. Programas do ensino Primário do Io ciclo. Maputo. 2015.

INDE. MINISTÉRIO DE EDUCAÇÃO E DESENVOLVIMENTO HUMANO.

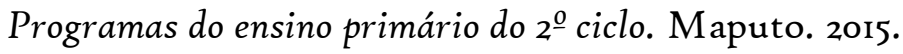

INDE. MINISTÉRIO DE EDUCAÇÃO E DESENVOLVIMENTO HUMANO. Programas do ensino primário do $3^{-0}$ ciclo. Maputo. 2015.

INDE. MINISTÉRIO DE EDUCAÇÃO E CULTURA. Plano Curricular do Ensino Secundário Geral. Imprensa Universitária da UEM. Maputo. 2007.

IPCC. Climate change: impacts, adaptation, and vulnerability. EUA. 2014.

LIMA, Gustavo. Mudanças climáticas e conservação social: riscos do aquecimento global. João Pessoa. Gaia Scientia. 2009.

LIMA, Gustavo e LAYRARGUES, P. P. Mudanças climáticas, educação e ambiente: Para além do conservadorismo dinâmico. Educar em revista. Curitiba. Editora UFPR. 2014.

MARCATTO, Celso. Educação ambiental: conceitos e princípios. Belo Horizonte. FEAM. 2002.

MARCONI, M. e LAKATOS, E. Fundamentos de Metodologia Científica. São Paulo. $5^{\underline{a}}$ Ed. Editora Atlas. 2003.

OLIVEIRA, Kelly. e MEDEIROS, Dalva. Educação ambiental: Abordagens teóricometodológicas. Mourão. Editora da FECILCAM. 2010.

MONJANE, A. R. et al. Manual de Educação Ambiental-Educação Ambiental: questões de cidadania. Maputo. Editora Educar. 2010.

REIGOTA, Marcos. O que é Educação Ambiental? São Paulo. Editora Brasiliense. I995. REPÚBLICA DE MOCAMBIQUE. CONSELHO DE MINISTROS. Plano de contingência 2019. Maputo. 2018. 
SANTOS, G. W. Modificando a escola através da Educação Ambiental: construindo a agenda 2 escolar. Dom Pio de Freitas. EEB. 2008.

SEARA F.G. Apontamentos de introdução à educação ambiental. Revista Ambiental. Ano I, V. I. 1987.

TRISTÃO, Martha. A Educação Ambiental na Formação de Professores: Redes de saberes. São Paulo. Editora Facitec. 2004.

UNESCO. Década da Educação das Nações Unidas para um Desenvolvimento Sustentável, 2005-2014: documento final do esquema internacional de implementação. Brasil. 2005. 